\title{
Health-related quality of life in Brazilian community-dwelling and institutionalized elderly: Comparison between genders
}

\author{
Gabriel Grizzo Cucato ${ }^{*}{ }^{*}$, Raphael Mendes Ritti-Dias ${ }^{1}$, Maysa Seabra Cendoroglo ${ }^{1}$, José Maria Maluf de Carvalho ${ }^{1}$, Fábio \\ Nasri $^{1}$, Maria Luiza Monteiro Costa ${ }^{1}$, Luciana Diniz Nagem Janot de Matos ${ }^{1}$, Fábio Gazelato de Mello Franco ${ }^{1}$

Study conducted at Hospital Israelita Albert Einstein (HIAE) São Paulo, SP, Brazil

Article received: $1 / 22 / 2016$ Accepted for publication: 2/15/2016 *Correspondence: Address: Av. Albert Einstein, 627/701 São Paulo, SP - Brazil Postal code: 05651-901 gacucato@gmail.com

\section{SUMMARY}

Objective: To compare the health-related quality of life (HRQL) indicators between institutionalized and community-dwelling elderly men and women.

Method: This was a cross-sectional study with a sample of 496 elderly men and women, surveyed by researchers at a private hospital that attends institutionalized and community-dwelling elderly. HRQL (World Health Organization Quality of Life), daily living activities (Katz questionnaire), and instrumental daily living activities (Lawton questionnaire), mini-mental state examination, handgrip strength test, and function capacity (timed up and go test) were obtained.

Results: Institutionalized men presented higher scores in physical and psychological domains of HRQL compared to elderly men living alone ( $\mathrm{p}<0.05$ ). Among women, the scores in all domains (physical, psychological, relationship, and environment) were similar between institutionalized and community-dwelling individuals.

Conclusion: Institutionalized elderly men reported better scores in physical and psychological domains of HRQL compared to their community-dwelling pairs, while both institutionalized and community-dwelling elderly women presented similar HRQL.

Keywords: aging, institutionalization, physical function, cognition.

\section{INTRODUCTION}

Improvements in life expectancy in Brazil have increased the demand for long-term care among elderly subjects $(\geq$ 65 years) ${ }^{1,2}$ Institutionalization has been considered an important alternative to provide adequate health care, especially for elderly who present poor functional capacity, advanced chronic diseases, and dependence.,

Although institutionalization improves elderly physical and cognitive functions and disease management, leading to an increase in life expectancy, their health-related quality of life (HRQL) is lower compared to community-dwelling elderly. ${ }^{5}$ However, it is unknown if these differences occur in a gender-dependent way. Given that the prevalence of disability and chronic diseases is higher in women, ${ }^{6}$ our hypothesis is that institutionalization could have greater impact on HRQL among women compared to men. Thus, the aim of this study was to compare the HRQL indicators between institutionalized and community-dwelling elderly men and women attended in a private hospital in Brazil.

\section{Method}

Sample

This was a cross-sectional study composed by 496 consecutive elderly men $(n=176)$ and women $(n=320)$ recruited in a Geriatric Hospital [Vila Mariana's unit of Hospital Israelita Albert Einstein (HIAE), São Paulo - Brazil]. Vila Mariana's unit of the HIAE is specialized in the care of elderly over 65 years. The patients attended included institutionalized and community-dwelling elderly individuals. In this unit, a multidisciplinary team (physicians, physiotherapists, psychologists, nurses, nutritionists and kinesiologists) provides optimal health and social support for the elderly. 
Patients included in our study were aged $\geq 65$ years and did not present any signs of dementia. They were interviewed by a trained nurse who performed all data collection. Information regarding HRQL, daily living activities, and instrumental daily living activities, as well as the mini-mental state examination was obtained. Moreover, they were also submitted to handgrip strength test and timed up and go (TUG) test. The subjects were divided into three groups: institutionalized, community-dwelling elderly living with their relatives, and community-dwelling elderly living alone.

This study was approved by the Clinical Research Ethics Committee of HIAE (process number: 0051.0.028.000-05). Moreover, the procedures were in accordance with the ethical standards of the Hospital's Committee of Ethics for Analysis of Research Projects on Human Experimentation and with the Helsinki Declaration of 1975 (revised in 1983).

\section{Primary outcome}

HRQL was assessed based on the Brazilian version of the World Health Organization Quality of Life (WHOQOL). This questionnaire consists of questions regarding four domains: physical health, psychological, social relationships, and environment. The score for each domain varies from 0 to 20, zero being considered the worst and 20 the best quality of life. ${ }^{7}$ The participants answered the questionnaire and when asked to help, the researcher was limited to re-reading the questions slowly. If the elderly presented difficulty in reading or understanding the questions, the assessment was conducted by interview.

\section{Secondary outcomes}

Daily living activities were assessed using Katz'questionnaire, ${ }^{8}$ which includes six items: bathing, getting dressed, going to the bathroom, getting from bed to a chair and vice-versa, maintaining sphincter continence, and eating. Instrumental daily living activities were analyzed using the Lawton-Brody scale $^{9}$ that includes eight items: using the telephone, shopping, cooking one's own meals, housecleaning, doing laundry, using transportation, taking medication, and managing finances. The mini-mental state examination was conducted to assess cognitive function, while the level of depression was assessed using a short form of the 15-item Geriatric Depression Scale. ${ }^{10}$ Functional capacity was evaluated by handgrip strength test ${ }^{11}$ and timed up and go test. ${ }^{12}$

\section{Statistical analysis}

Descriptive statistics was performed using frequency distribution and mean \pm standard deviation. The groups were compared using one-way ANOVA for continuous variables, and Pearson chi-square test for categorical variables. For all inferential analysis, a $\mathrm{p}<0.05$ was considered significant.

\section{Results}

Figure 1 shows the characteristics of the sample. Men presented higher prevalence of stroke and coronary artery disease, while women presented higher prevalence of depression. Institutionalized men and women were older, had higher prevalence of functional disability, lower cognitive function, and higher prevalence of stroke compared to the other two groups ( $\mathrm{p}<0.01)$. Women living alone presented a higher prevalence of coronary artery disease and depression compared to the other two groups ( $\mathrm{p}<0.05)$. All other variables were similar among the three groups $(\mathrm{p}>0.05)$.

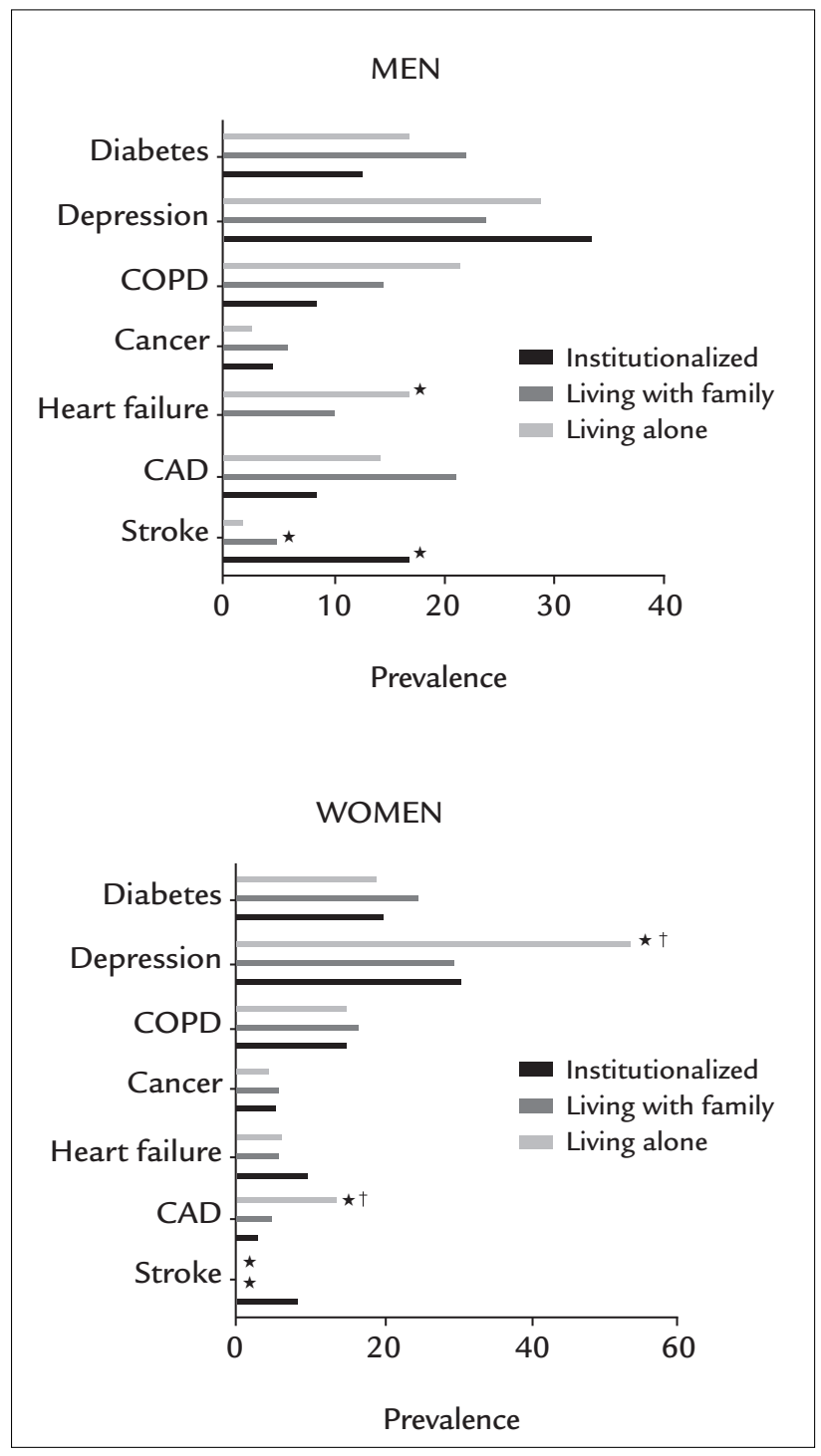

FIGURE 1 Characteristics of the sample.

COPD: chronic obstructive pulmonary disease; CAD: coronary artery disease. *Difference from institutionalized $(p<0.05)$; $†$ difference from living with family $(p<0.05)$ 
Figure 2 presents the HRQL indicators in elderly men. Institutionalized men presented higher scores in physical and psychological domains compared to elderly men living alone $(\mathrm{p}<0.05)$. In addition, the score in psychological domain was higher in institutionalized men compared to elderly men living with their families $(\mathrm{p}<0.05)$.

Figure 3 presents the HRQL in elderly women. The scores in all domains (physical, psychological, relationship, and environment) were similar among the three groups ( $p>0.05)$.

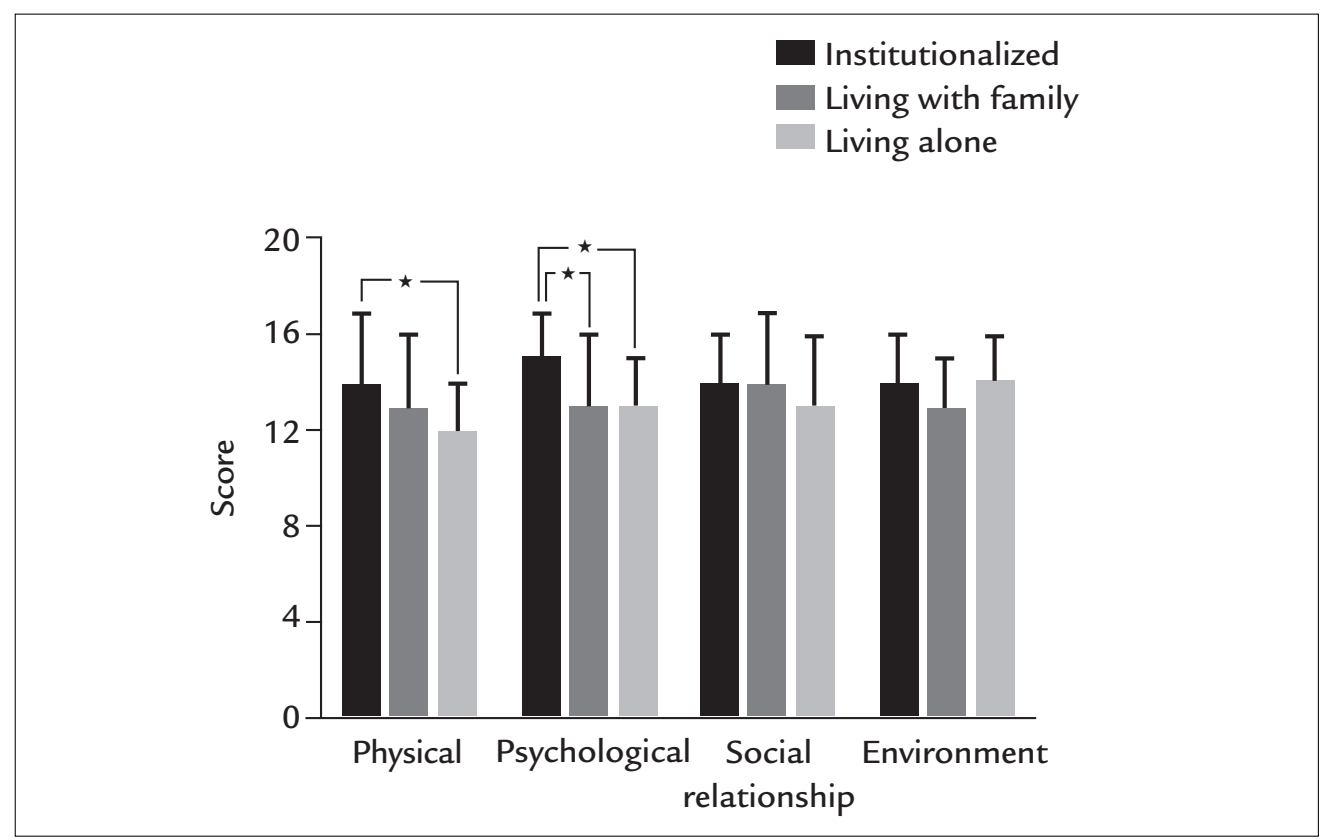

FIGURE 2 Health-related quality of life indicators in elderly men living in institutions ( $n=24)$, with family $(n=110)$, or alone $(n=42)$.

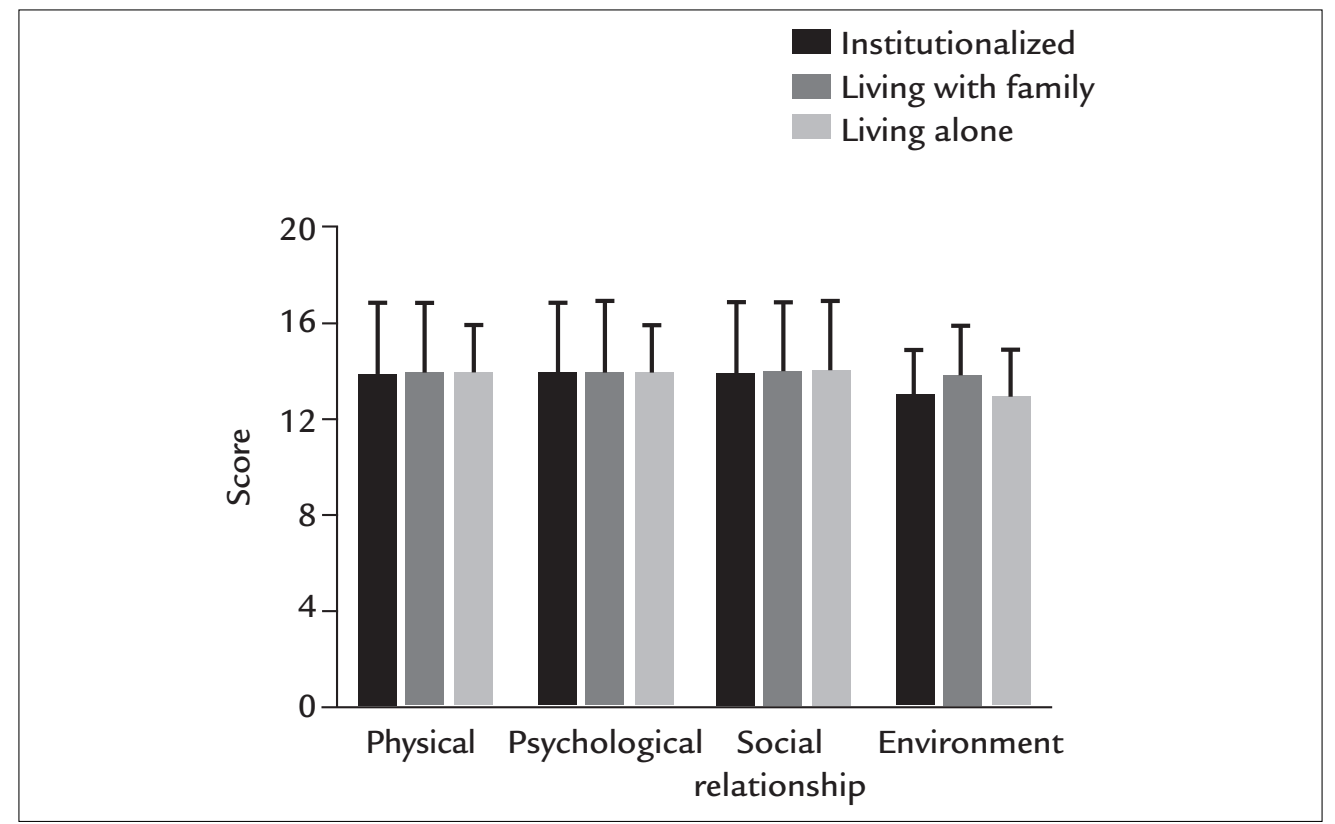

FIGURE 3 Health-related quality of life indicators in elderly women living in institutions ( $n=75)$, with family $(n=170)$, or alone $(n=75)$. 


\section{Discussion}

The main results of this study were: (i) institutionalized elderly presented similar functional performance compared to community-dwelling elderly; (ii) institutionalized elderly men and women were older and presented lower cognitive function compared to community-dwelling elderly; (iii) institutionalized men presented higher scores in physical and psychological of HRQL domains in comparison with community-dwelling elderly; and (iv) both institutionalized and community-dwelling elderly women had similar HRQL.

In the presented study, although institutionalized men and women were older than community-dwelling elderly, they presented similar performance in physical tests, including handgrip strength and timed up and go. These results reflect the rehabilitation program available at the institution, in which a multidisciplinary team (physicians, physiotherapists, psychologists, nurses, nutritionists and kinesiologists) provides optimal health (exercise programs, nutritional counseling) and social support for elderly subjects, with adequate stimulus for improvements in elderly physical capacity. Despite the positive physical profile, the institutionalized elderly participants were less capable of performing basic and instrumental activities of daily living. This was probably caused by the lower cognitive capacity of institutionalized elderly compared to community-dwelling elderly individuals ${ }^{13}$ since cognitive functions are strongly related to the capacity to perform basic and instrumental daily activities. ${ }^{14-16}$

Previous studies have suggested an association between dependence and lower perception of HRQL. ${ }^{17} \mathrm{How}-$ ever, in the present study, despite high dependence, HRQL indicators were similar or better in institutionalized compared to the community-dwelling elderly participants. Factors that included elderly physical fitness and the facilities offered in the institution (e.g. more accessible spaces, short hallways, handrails, and walking path to provide a safety sensation) and the presence of a full-time health staff probably improved their HRQL perception.

The differences in HRQL scores between institutionalized and community-dwelling elderly occurred in a gender-dependent fashion. Institutionalized men showed higher scores in physical and psychological domains compared to community-dwelling elderly, while no significant differences in any domain of health-related quality of life were observed among women. Given that HRQL is related to the perception of life, men probably have a better perception of their physical fitness and cognitive function. Moreover, chronic conditions such as arthritis, back problems, or depression are found more frequently in women ${ }^{6}$ and these chronic conditions have a greater effect on HRQL.

The results of the present study reveal some important clinical aspects. First, this study provides further information on HRQL indicators among the elderly living in different settings, and how elderly men and women perceive their HRQL. The similar and/or better results observed in institutionalized elderly compared to community-dwelling elderly suggest that the maintenance of HRQL with aging is possible in elderly individuals living in an adequate environment.

The cross-sectional design is the main limitation of our study, since it does not allow causality, and our results should therefore be confirmed by longitudinal studies. The groups were not matched, as institutionalized elderly were older and presented a lower cognitive function compared to community-dwelling elderly. However, this represents the different profile of institutionalized and community-dwelling elderly populations. The number of institutionalized and community-dwelling men was lower than the number of community-dwelling elderly individuals living with their families, which probably represents the pattern of distribution of elderly men living in different conditions. Finally, the subjects were recruited in a single institution and whether similar results are observed in other places is unknown.

\section{Conclusion}

The results of our study indicated that institutionalized elderly men reported better scores in physical and psychological domains of HRQL compared to communitydwelling individuals, while both institutionalized and community-dwelling elderly women presented similar HRQL.

\section{ACKNOWLEDGMENTS}

The authors wish to extend their grateful thanks to all the patients of the study.

\section{Resumo}

Qualidade de vida relacionada à saúde em idosos brasileiros residentes em comunidade e institucionalizados: comparação entre gêneros

Objetivo: comparar os indicadores de qualidade de saúde de vida (QV) entre idosos homens e mulheres institucionalizados e aqueles que vivem na comunidade sozinhos ou com a família. 
Método: estudo transversal com amostra composta por 496 idosos homens e mulheres, entrevistados por pesquisadores em um hospital privado que atende idosos institucionalizados e da comunidade. Os indicadores de QV (World Health Organization Quality of Life), atividades da vida diária (Katz questionnaire), atividades instrumentais da vida diária (Lawton questionnaire), exame do estado mental (mini-mental), teste de força de preensão manual (Handgrip) e capacidade funcional (Timed up to go) foram obtidos.

Resultados: homens institucionalizados apresentaram maiores escores de QV no domínio físico e psicológico em relação aos idosos que vivem na comunidade sozinhos $(\mathrm{p}<0,05)$. Nas mulheres, os escores em todos os domínios de QV (físico, psicológico, relações sociais e ambientais) foram semelhantes entre as idosas institucionalizadas e as residentes na comunidade, que vivem sozinhas ou com a família.

Conclusão: homens idosos institucionalizados relataram melhores escores de QV nos domínios físico e psicológico em comparação com pares que vivem na comunidade, enquanto, em mulheres, resultados similares foram observados nas idosas institucionalizadas e da comunidade.

Palavras-chave: envelhecimento, institucionalização, função física, cognição.

\section{References}

1. Belon AP, Lima MG, Barros MB. Gender differences in healthy life expectancy among Brazilian elderly. Health Qual Life Outcomes. 2014; 12:12-88.

2. Luppa M, Luck T, Weyerer S, König HH, Brähler E, Riedel-Heller SG. Prediction of institutionalization in the elderly. A systematic review. Age Ageing. 2010; 39(1):31-8.
3. Del Duca GF, Silva SG, Thume E, Santos IS, Hallal PC. Predictive factors for institutionalization of the elderly: a case-control study. Rev Saúde Pública. 2012; 46(1):147-53

4. De Luca d'Alessandro E, Bonacci S, Giraldi G. Aging populations: the health and quality of life of the elderly. Clin Ter. 2011; 162(1):e13-8.

5. Reimer MA, Slaughter S, Donaldson C, Currie G, Eliasziw M. Special care facility compared with traditional environments for dementia care: a longitudinal study of quality of life. J Am Geriatr Soc. 2004; 52(7):1085-92.

6. Barnett K, Mercer SW, Norbury M, Watt G, Wyke S, Guthrie B. Epidemiology of multimorbidity and implications for health care, research, and medical education: a cross-sectional study. Lancet. 2012; 380(9836):37-43.

7. Study protocol for the World Health Organization project to develop a Quality of Life assessment instrument (WHOQOL). Qual Life Res. 1993; 2(2):153-9.

8. Katz S. Assessing self-maintenance: activities of daily living, mobility, and instrumental activities of daily living. J Am Geriatr Soc. 1983;31(12):721-7.

9. Lawton MP, Brody EM. Assessment of older people: self-maintaining and instrumental activities of daily living. Gerontologist. 1969; 9(3):179-86.

10. de Craen AJ, Heeren TJ, Gussekloo J. Accuracy of the 15-item geriatric depression scale (GDS-15) in a community sample of the oldest old. Int J Geriatr Psychiatry. 2003; 18(1):63-6.

11. Roberts HC, Denison HJ, Martin HJ, Patel HP, Syddall H, Cooper C, et al. A review of the measurement of grip strength in clinical and epidemiological studies: towards a standardised approach. Age Ageing. 2011; 40(4):423-9.

12. Podsiadlo D, Richardson S. The timed "Up \& Go": a test of basic functional mobility for frail elderly persons. J Am Geriatr Soc. 1991; 39(2):142-8.

13. Jellinger KA. Pathology and pathogenesis of vascular cognitive impairment - a critical update. Front Aging Neurosci. 2013; 5:17.

14. Doi T, Shimada H, Makizako H, Lee S, Park H, Tsutsumimoto K, et al. Cognitive activities and instrumental activity of daily living in older adults with mild cognitive impairment. Dement Geriatr Cogn Dis Extra. 2013; 3(1):398-406

15. Johansson MM, Marcusson J, Wressle E. Cognition, daily living, and healthrelated quality of life in 85 -year-olds in Sweden. Neuropsychol Dev Cogn B Aging Neuropsychol Cogn. 2012; 19(3):421-32.

16. Yoshida D, Ninomiya T, Doi Y, Hata J, Fukuhara M, Ikeda F, et al. Prevalence and causes of functional disability in an elderly general population of Japanese: the Hisayama study. J Epidemiol. 2012; 22(3):222-9.

17. Dobrzyn-Matusiak D, Marcisz C, Bak E, Kulik H, Marcisz E. Physical and mental health aspects of elderly in social care in Poland. Clin Interv Aging. 2014; 9:1793-802. 